\title{
Difficulties in diagnosing and treating nasal rhinoscleroma: A case study
}

\section{Trudności w diagnostyce i leczeniu twardzieli błony śluzowej nosa - opis przypadku}

\author{
Paweł Poniatowski ${ }^{1, A-F}$, Klaudiusz Łuczak ${ }^{1, B, D, F}$, Kamil Nelke ${ }^{2, B, D-F}$ \\ ${ }^{1}$ Department of Maxillo-Facial Surgery, Wroclaw Medical University, Poland \\ ${ }^{2}$ Department of Maxillo-Facial Surgery, $4^{\text {th }}$ Military Hospital, Wrocław, Poland \\ A - research concept and design; B - collection and/or assembly of data; C - data analysis and interpretation; \\ $D$ - writing the article; $E$ - critical revision of the article; $F$ - final approval of the article
}

Address for correspondence

Kamil Nelke

E-mail: kamil.nelke@gmail.com

\section{Funding sources}

None declared

\section{Conflict of interest}

None declared

Received on June 13, 2017

Reviewed on July 28, 2017

Accepted on September 6, 2017

\begin{abstract}
For many years scleroma was considered to be a neoplastic tumor. First findings of this disease came from the $4^{\text {th }}$ century. In the $18^{\text {th }}$ century it was also called the leprosy of the nose. In 1840, a Polish surgeon was the first in the world to describe rhinoscleroma as a "chronic nose cancer". In late 1877, Jan Mikulicz-Radecki classified this scleroma as rhinoscleroma, an inflammatory disease with the most common occurrence in the nasal cavity. Because of very rare cases of this disease reported nowadays (endemic), its treatment is challenging. The disease manifests itself as a symptomatic mass causing mostly an obstruction of nasal breathing or even local nose bleeds, and infiltrates the surrounding structures of the nose and sinuses. Difficult accurate clinical diagnosis of this disease seems to be the main problem in its early detection and treatment. Apart from a surgical excisional biopsy or more radical surgical approach, additional antibiotic treatment, along with routine checkups by an infectious diseases specialist, should be maintained.
\end{abstract}

A very rare and unusual case of a 75-year-old retired otolaryngologist diagnosed with a symptomatic mass in the nasal cavity, treated previously by unknown methods and without any success, will be presented. It is worth noticing that either the patient's economic status or his past job as an otolaryngologist might be related to the occurrence of rhinoscleroma as the possible route of infection.

Key words: rhinoscleroma, nasal cavity, diagnostic difficulties, treatment outcomes

Słowa kluczowe: twardziel błony śluzowej nosa, jama nosowa, trudności diagnostyczne,wyniki leczenia

D0I

$10.17219 / \mathrm{dmp} / 76848$

Copyright

() 2017 by Wroclaw Medical University

and Polish Dental Society

This is an article distributed under the terms of the

Creative Commons Attribution Non-Commercial License

(http://creativecommons.org/licenses/by-nc-nd/4.0/) 
Rhinoscleroma can be found in many various anatomical parts of the entire respiratory tract. Because of civilizational and medical development, its occurrence in Europe is very rare today. ${ }^{1}$ The WHO sources estimate its occurrence at about 6 cases between 2000 and 2004 . Other reports rarely explain its occurrence in Europe. ${ }^{1-3}$ The most common geographical occurrence sites for this disease are South America, India, south-eastern Asia and Africa. Most studies report an overall higher occurrence in women than in men, with the age ratio being about 15-35 years. ${ }^{4}$ Lack of hygiene, poor economic conditions, malnutrition and prolonged contact with an infected person seem to be the most common epidemiologic factors for infection. ${ }^{1,4}$ Rhinoscleroma (scleroma) is a very rare disease of the respiratory tract and is still considered to be incurable in some clinical stages. ${ }^{5}$ In most cases it commonly manifests itself as a proliferative chronic inflammation caused by Klebsiella rhinoscleromatis, a Gramnegative rod bacillus, which is also called the Firsch bacillus. ${ }^{3,6}$ Because of the rareness of this disease today, its accurate diagnosis might be troublesome and there may be many misdiagnoses. Excisional biopsy or ablative surgery followed by microbiological scrubs seems to be the treatment of choice. ${ }^{4,7}$

Rhinoscleroma (RS) is characteristic for its distinctive growth and has 3 clinical stages. ${ }^{5,8}$ The $1^{\text {st }}$ one, the atrophic stage, is characterized by a nonspecific rhinitis, which sometimes progresses into a purulent nasal secretion, while the $2^{\text {nd }}$ one is the granulomatous stage. This one is characterized by the development of nodules and polyps in the nasal cavity. It is the time when the nosewings begin to be asymmetrical. The final stage of RS is the sclerotic stage, characterized by the destruction of the nasal cartilage and nasal septum, the obstruction of the nasal cavity with granulation tissue and the obliteration of the pharyngeal opening of the auditory tube. In the most severe cases, the adhesion between the soft palate and the posterior pharyngeal wall is reported., $4,9,10$

Histopathological characteristics in RS include hard inflammatory infiltrations in the area of the anatomical recesses and openings of the respiratory tract. The infiltrations contain a large number of inflammatory cells (granulocytes, lymphocytes, plasmocytes, and histiocytes) and a characteristic formation of various granulation tissues, blood vessels or/and connective tissues. In these tumor masses, the characteristic Mikulicz cells are also found. ${ }^{8,10}$ These foamy cells contain many vacuoles filled with numerous Klebsiella rhinoscleromatis bacilli, which are common and characteristic histopathologic findings confirming scleroma. Another feature is the presence of Russel bodies - cells containing hyaline. . $^{3,711,12}$

Differential diagnosis should include bacterial (actinomycosis, tuberculosis, syphilis, leprosy), fungal (histoplasmosis, blastomycosis, paracoccidioidomycosis, sporotrichosis) and even parasite infection (mucocutaneous leishmaniasis). ${ }^{2,9,10}$ Rhinoscleroma can also have similar clinical manifestations as various inflammatory and neoplastic processes, such as basal cell carcinoma, nasopalatine duct cyst, sarcoidosis, verrucous carcinoma, wegener granulomatosis, central giant cell granuloma, histiocytosis $\mathrm{X}$, lymphoma (lethal midline granuloma-FLMG or Hodgkins) or other neoplastic diseases, which also should be taken into consideration. Other findings should include: nasal polyposis, extranodal Rosai-Dorfman disease, vasculitis, paracoccidioidomycosis, cocaine-induced midline destructive erosions, foreign body granulomas, or others. ${ }^{2,8}$

In the cases of chronic growth, early stages of the disease are not clear and mostly underestimated or neglected. Slowly growing masses with progressive symptoms arising from the surrounding anatomical area of the respiratory tract should be carefully evaluated and never neglected. Another important issue concerning RS are inaccurate diagnostic methods and the lack of the ability to visualize clearly the pathology. ${ }^{11}$

\section{Case report}

A 75-year-old, generally healthy retired otolaryngologist without any previous medical history was referred to the department with a complete obstruction of the nasal cavity, anosmia, rhinophonia, pain in the naso-maxillary area of the incisive bone and floor of the nasal cavity. Additionally, breathing problems and swelling of lymph nodes were found. The first symptoms were related with maxillary incisor tooth pain and rhinitis. A diagnostic biopsy indicated foamy cells with Klebsiella rhinoscleromatis infection. Routine CT-examination revealed the presence of pathologic tissues within the nasal cavity and maxillary sinuses, manifesting as an obstruction with granulomatous tissue and bone destruction of surrounding structures, including vomer, nasal septum, and maxillary sinus with inferior and middle nasal conchae (Fig. 1). Laryngoscopy revealed widening of the vocal folds without any involvement of the epipharynx; however, a large amount of secretion due to the obstruction of the nasal cavity was

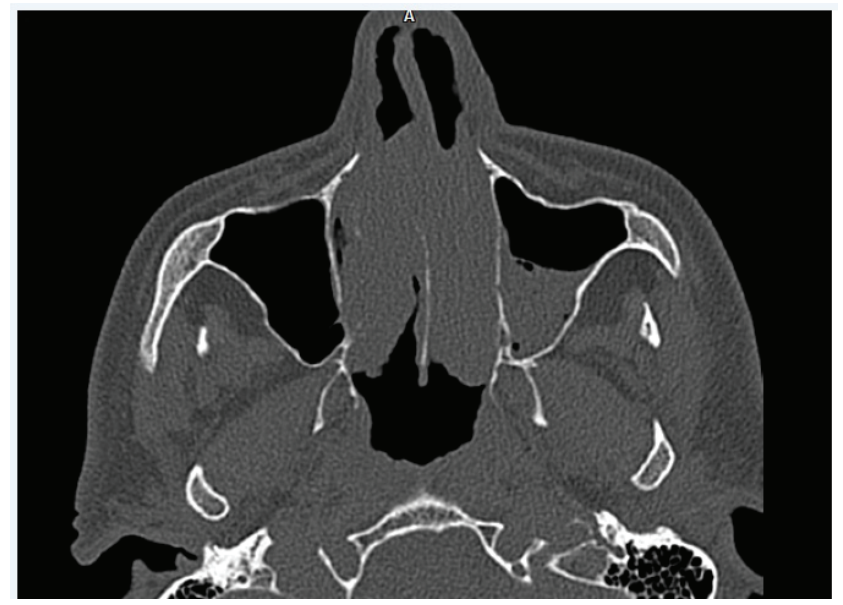

Fig. 1. Pre-operative compute tomography with visible tumor masses 


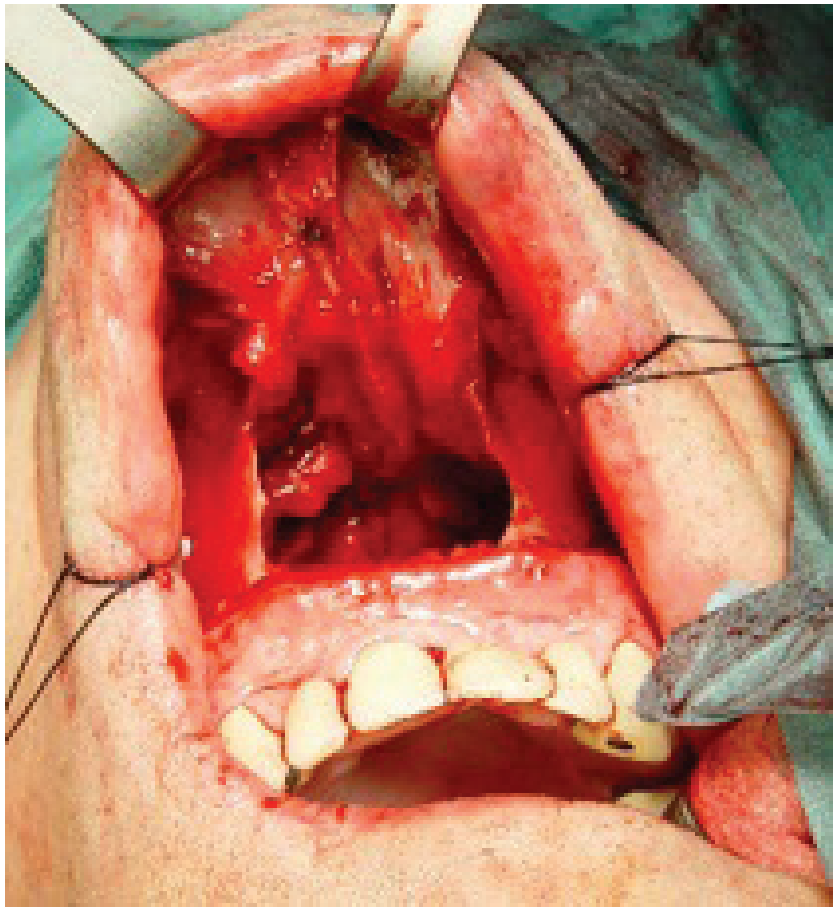

Fig. 2. Surgical deglovingapproach

found. Surgery included the dissection of swollen right lymph nodes-IB and part of nasal cavity from the degloving maxillary approach (Fig. 2). The entire content of the nasal cavity was removed along with the granulating tissue, inferior and middle nasal conchae, nasal septum and the additional nodule perforating to the epipharynx. Bone fragments were removed and an additional curettage of the resection site was made. Microbiological scrubs from deep inside the tumor mass along with tissues scheduled for a histopathological evaluation were sent for further investigation to 3 independent histopathological clinics in major university towns to confirm the diagnosis and exclude any possible misdiagnosis (Fig. 3, 4). Nasal packing with antibiotics ( $2 \%$ neomycin ointment - aminoglycoside) was applied around 2 silicone tubes to maintain adequate nasal breathing and enable the secure drainage

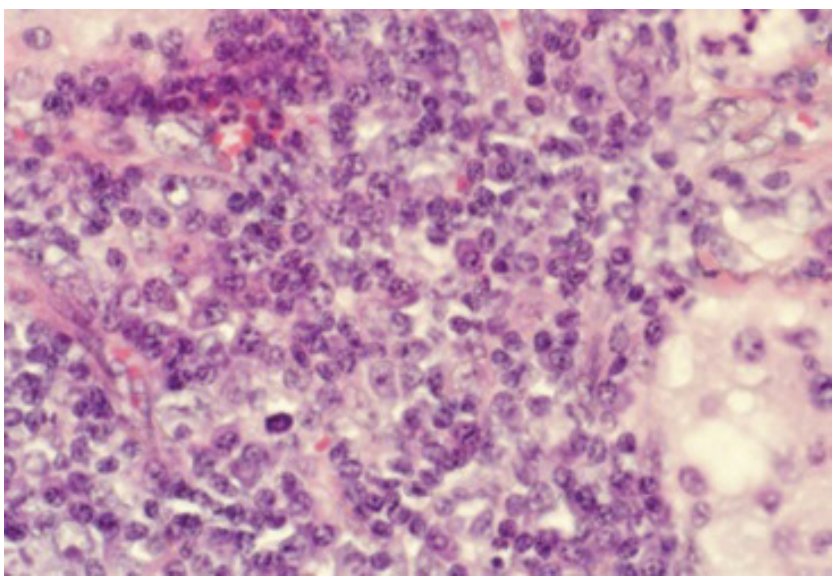

Fig. 3. Histopathological evaluation $(H+E$, staining $25 x)$

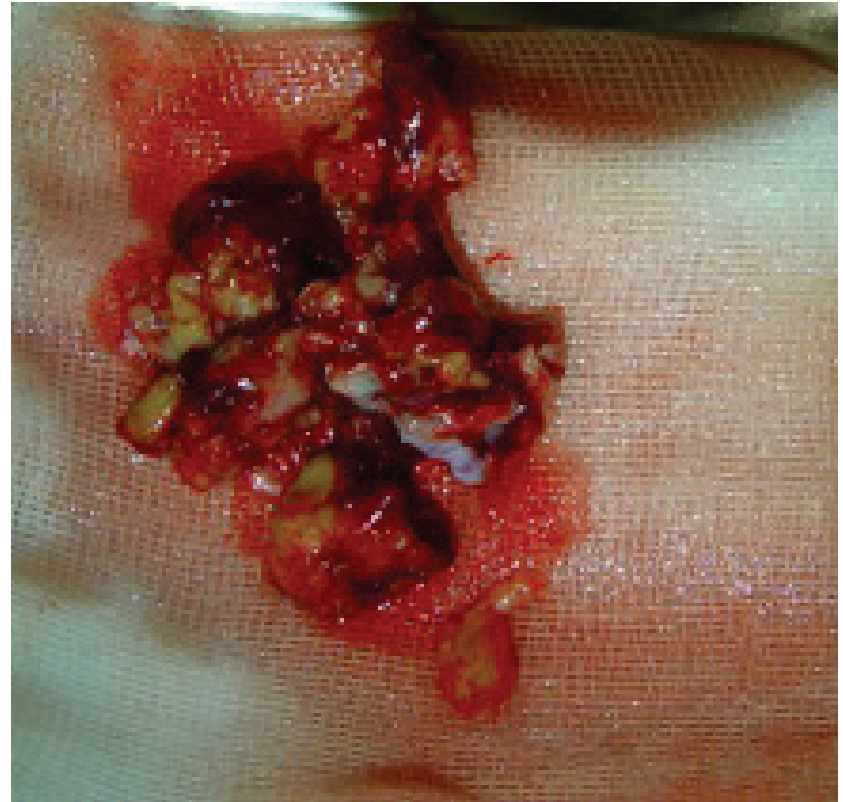

Fig. 4. Microscopic specimen

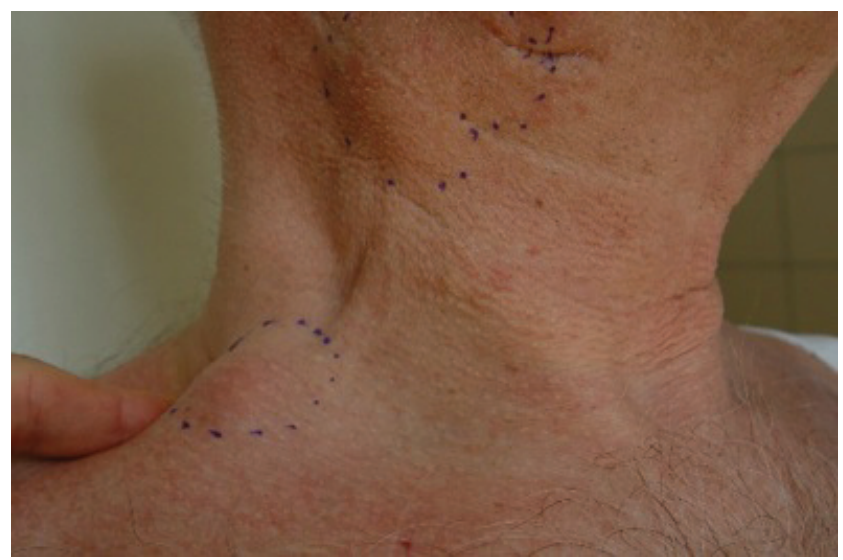

Fig. 5. Swollen lymph nodes (marked with blue circles)

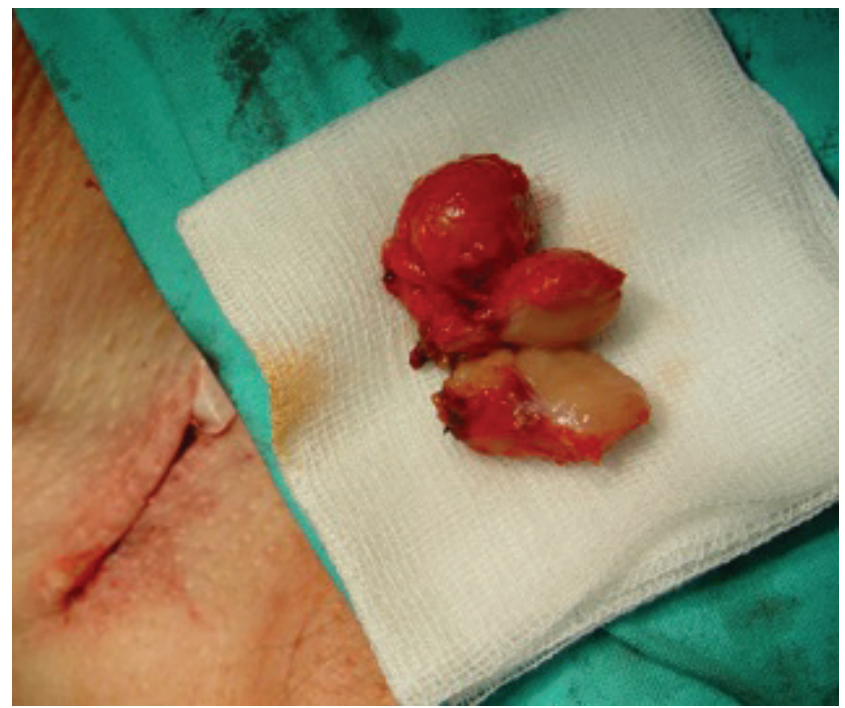

Fig. 6. Excised swollen lymph nodes 
of blood and other exudation for $48 \mathrm{~h}$. The next step of the surgery was focused on the removal of 3 swollen nodes in the right submandibular area (IB) and right supraclavicular area (Fig. 5, 6). Histopathological evaluation described the main tumor as a massive inflammatory infiltration consisting of plasmatic cells, lymphocytes $\mathrm{T}$ and $\mathrm{B}$ with a huge amount of foamy cells, namely the Mikulicz cells. Additional immunohistochemistry revealed the presence of Bcl-2(+); CD20(+); CD3(+); MAC387(+); CD68(+) and Ki-67(-) antigens. Dissected swollen lymph nodes were also identified as rhinoscleroma.

The surgical period went without complications. The patient was treated with targeted antibiotic treatment Cipronex $^{\circledR}$ (fluoroquinolonum; $2 \times 500$ mg intravenously) and Doxycycline TZF $^{\circledR}$ (tetracyclinum; $2 \times 100 \mathrm{mg} / \mathrm{mL}$ intravenously), while in the department for 5 days, and then after discharge for additional 3 weeks. In a routine antibacterial swab from the operated area after 3 weeks, no bacterial or fungal infections were present. The $2^{\text {nd }}$ part of treatment was scheduled at The Regional Infectious Diseases Centre with the same mentioned antibiotics. Control CT and nasopharynx endoscopy after 6 months revealed no signs of nasal obstruction or visible recurrence of RS and no tumor mass (Fig. 7). So far after two years, no disease recurrence was noticed.

\section{Discussion}

Rhinoscleroma of the sinonasal tract is rare in the European population. ${ }^{4,12}$ When present, in most cases it is found in the upper respiratory tract, mimicking tumorlike hard inflammatory infiltrations. ${ }^{13-16}$ In some cases, its growth is misdiagnosed with cancer occurrence. ${ }^{3,10,16}$ In available data a large number of inflammatory cells which corresponds with the degree of destruction of the nasal cartilage and nasal septum were found. ${ }^{15-17}$ A growing and proliferative tumor mass causes the obstruction

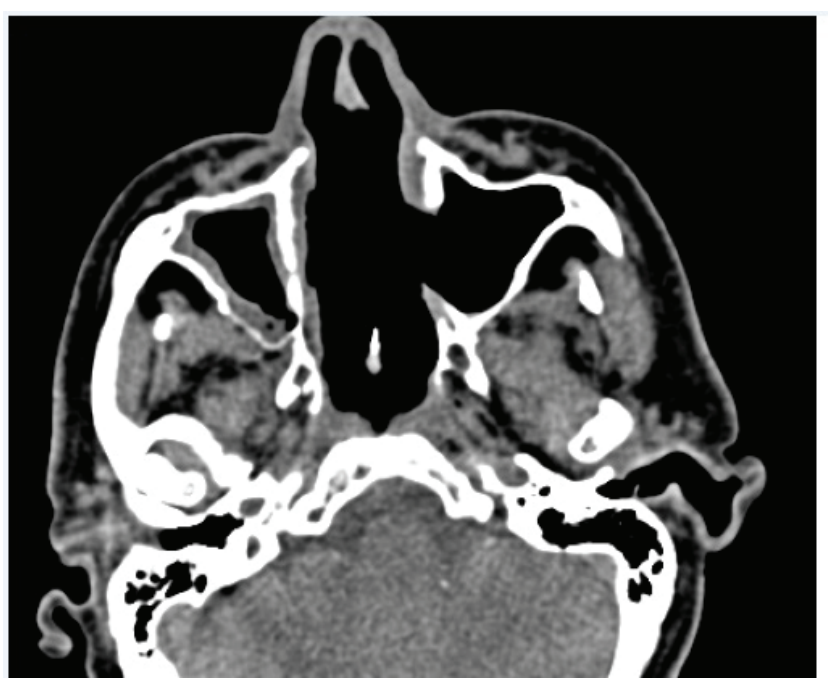

Fig. 7. Six-month post-op computed tomography of the nasal cavity with granulation tissue formation and the obliteration of the pharyngeal opening of the auditory tube. ${ }^{18,19}$ Additional studies report the elevation of IL-10 and also other indirect inflammation markers levels. ${ }^{13,19}$ This finding might be one of the positive markers for diagnostics of RS; however, additional levels of other inflammatory markers such as CRP (C-reactive protein) and procalcitonin levels might vary in the cases with or without a severe inflammation component. ${ }^{11,13,14,20}$ It seems that a biopsy with microbiological scrubs are the most accurate factors for identifying RS. ${ }^{2-4,19}$ A careful clinical examination should always be performed. In the most severe cases, tumor tissue mass adhesion to the soft palate and the posterior pharyngeal wall was reported. ${ }^{6,7}$ In some rare cases, RS can mimic nasal polyposis or lead to the enlargement and asymmetry of the nasal septum. ${ }^{14,15}$ The presented case shows how hard it was and how long it took to diagnose this disease. This worrisome fact corresponds to the small amount of RS occurrence in Europe. ${ }^{16}$ It turns out that even in times when we have at our disposal state-of-the-art imaging techniques (such as computed tomography, magnetic resonance imaging, videofiberoscopy), pathomorphological tests (such as immunohistochemistry) and almost unlimited access to knowledge, the occurrence of rare or almost forgotten diseases in some geographical areas is troublesome. ${ }^{18}$ Nevertheless, nasal and oral cavity endoscopy and scheduled computed tomography imaging still remain basic diagnostic approaches. Differential diagnosis should take into account many other nasal cavity diseases, especially infiltrative and inflammatory ones, whose exclusion or co-occurrence could improve the diagnosis.

The treatment of rhinoscleroma is challenging. When an excessive RS growth is present, a rhinosporidiosis progress might lead to a life-threatening obstruction or stenosis of the lower respiratory tract. ${ }^{17,21}$ In those situations, bronchoscopic and/or endoscopic evaluation and treatment should be scheduled. ${ }^{10,15,20,22}$ As scleroma was considered to be incurable, many patients must continue regular check-ups in a maxillofacial, laryngology, pulmonology and infectious diseases specialists. Nowadays, the most frequent method of treating scleroma is antibiotic therapy. ${ }^{19}$ When streptomycin was added to the treatment, most symptoms decreased significantly. Currently, cases of scleroma are treated with fluoroquinolones, ex. rifampicin as well as with tetracycline and co-trimoxazole. In the authors' opinion, in some cases it is worth considering surgical treatment accompanied by pharmacological treatment. ${ }^{21}$ Antibacterial treatment without a radical surgical excision is not recommended in cases of infiltration and destruction of nasal cavity walls. The presented case emphasizes that the surgical procedure stopped the disease from spreading, improved the quality of the patient's life and made it possible to diagnose the disease. Further pharmacological treatment sustained the therapeutic effect of the surgical treatment. ${ }^{17,20,22}$ 


\section{Conclusions}

The presented case underlines a possible etiological factor for the infection in components such as numerous contact with people diagnosed with ear, nose and throat diseases. The authors' study mentioned the etiological factors related with the patient's past job as a laryngologist. Radical surgery seems to be the treatment of choice in order to avoid the spread of the disease. On the other hand, the degloving approach seems to influence later proper nasal shape and function. If the patient is reporting an occurrence of a saddle nose, additional cosmetic surgery can be performed. The adequate time for it is estimated at 12 months from the previous surgery and when no recurrence of $\mathrm{RS}$ is noted.

\section{References}

1. Chan TV, Spiegel JH. Klebsiella rhinoscleromatis of the membranous nasal septum. J Laryngol Otol. 2007;21:998-1002.

2. Simão I, Gaspar I, Faustino R, Brito MJ. Rhinoscleroma in a 5-yearold Portuguese Child. Pediatr Infect Dis J. 2014;33:774-775.

3. Chou TC, Tsai KB, Lee CH. Emperipolesis is not pathognomonic for Rosai-Dorfman disease: Rhinoscleroma mimicking Rosai-Dorfman disease, a clinical series. J Am Acad Dermatol. 2013;69:1066-1067.

4. Botelho-Nevers E, Gouriet F, Lepidi H, et al. Chronic nasal infection caused by Klebsiella rhinoscleromatis or Klebsiella ozaenae: Two forgotten infectious diseases. Int J Infect Dis. 2007;11:423-429.

5. Allah KC, Kossoko H, Assi Djè Bi Djè V, Yéo $S$, Richard Kadio M. Giant rhinoscleroma. Rev Stomatol Chir Maxillofac Chir Orale. 2013;114:184-186.

6. Ammar ME, Rosen A. Rhinoscleroma mimicking nasal polyposis Ann Otol Rhinol Laryngol. 2001;110:290-292.

7. Fuchs HA, Tanner SB. Granulomatous disorders of the nose and paranasal sinuses. Curr Opin Otolaryngol Head Neck Surg. 2009;17:23-27.

8. Kulkarni MA, Mudholkar GV, Acharya SA, Ramteke VR. Histopathological study of lesions of nose and paranasal sinuses. Ind J Otolaryngol Head Neck Surg. 2012;64:275-279.

9. Garg D, Mathur K. Clinico-pathological study of space occupying lesions of nasal cavity, paranasal sinuses and nasopharynx. J Clin Diag Res. 2014;8:4-7.

10. Maru YK, Munjal S, Gupta Y. Brush cytology and its comparison with histopathological examination in cases of diseases of the nose. J Laryngol Otol. 1999; 113:983-987.

11. Busch RF. Rhinoscleroma occurring with airway obstruction. Otolaryngol Head Neck Surg. 1993;109:933-936.

12. de Pontual L, Ovetchkine P, Rodriguez D, et al. Rhinoscleroma: A French national retrospective study of epidemiological and clinical features. Clin Infect Dis. 2008;47:1396-1402.

13. Fevre C, Almeida AS, Taront S, Pedron T, Huerre M, Prevost MC A novel murine model of rhinoscleroma identifies Mikulicz cells, the disease signature, as IL-10 dependent derivatives of inflammatory monocytes. EMBO Mol Med. 2013;5:516-530.

14. Ammar ME, Rosen A. Rhinoscleroma mimicking nasal polyposis. Ann Otol Rhinol Laryngol. 2001;110:290-292.

15. Chan TV, Spiegel JH. Klebsiella rhinoscleromatis of the membranous nasal septum. J Laryngol Otol. 2007;121:998-1002.

16. Gaafar HA, Gaafar AH, Nour YA. Rhinoscleroma: An updated experience through the last 10 years. Acta Otolaryngol. 2011;131:440-446.

17. Abalkhail A, Satti MB, Uthman MA, Al Hilli F, Darwish A, Satir A. Rhinoscleroma: A clinicopathological study from the Gulf region. Singapore Med J. 2007;48:148-151.

18. Zhong Q, Guo W, Chen X. Rhinoscleroma: A retrospective study of pathologic and clinical features. J Otolaryngol Head Neck Surg. 2011;40:167-174.

19. Sood N, Sood S, Arora S. Cytohistological features of rhinoscleroma. Ind J Pathol Microbiol. 2011;54:806-808.
20. Batsakis JG, el-Naggar AK. Rhinoscleroma and rhinosporidiosis. Ann Otol Rhinol Laryngol. 1992;101:879-882.

21. Sun Y, Sun W, Lu X. Clinical analysis of 19 cases of scleroma respiratory treated surgically. Lin Chuang Er Bi Yan Hou Ke Za Zhi. 1998;12:314-316.

22. Al Jahdali $H$, Bamefleh $H$, Memish $Z$, Al-Zuwayed $M, A$ I Othman A. Upper airway obstruction due to rhinoscleroma: Case report. J. Chemother. 2001;13:69-72. 